Educación Física y Ciencia, vol. 19, n 1, e019, junio 2017. ISSN 2314-2561

Universidad Nacional de La Plata.

Facultad de Humanidades y Ciencias de la Educación.

Departamento de Educación Física

\title{
Voleibol sentado: un deporte que da sentido a la vida
}

\author{
Sitting volleybal: a sport that gives sense to the life
}

\author{
Efraín Muñoz Galíndez *; Sandra Montes Mora * \\ *Universidad Autónoma del Cauca, Colombia | efrainm_22@hotmail.com ; \\ sandramontesmora@gmail.com
}

\section{PALABRAS CLAVE RESUMEN}

Deporte adaptado

Víctima del conflicto

armado

Minas antipersonas

Sentido

\section{KEYWORDS}

Adapted sports

Armed conflict victims

Anti-personnel mines

Sense
Este artículo es el resultado de una investigación que tuvo como objetivo interpretar el sentido que un grupo de deportistas de voleibol sentado le dan a este deporte. Las personas que permitieron el desarrollo de este estudio son ex-militares que en su quehacer profesional perdieron una de sus extremidades a manos de las minas antipersonas, sembradas por grupos al margen de la ley. Para ahondar en la subjetividad de los deportistas y develar sus sentires, se utilizó el enfoque cualitativo y como técnicas de recolección de datos la entrevista en profundidad y el grupo focal; los relatos fueron analizados y categorizados bajo la técnica de análisis de contenido y los lineamientos de la teoría fundada. Los resultados evidencian que la amputación es un episodio que cambió sus vidas sumergiéndolos en un mundo de incertidumbres, desafíos y retos que debieron sortear junto con sus familiares y personas allegadas. En este duelo las víctimas encontraron en el voleibol sentado un espacio para reencontrase con ellos mismos y sus pares, dándole nuevamente un sentido a sus vidas. Por ello, conciben el equipo de voleibol como una familia que les ha enseñado que los límites van más allá de la condición física.

\section{ABSTRACT}

This paper is the result of an investigation whose aim was to interpret the sense that a group of players of sitting volleyball gives to this sport. Those that allowed the development of this study are ex-military officers who, in their professional duty, lost one of their limbs as a result of antipersonnel mines, planted by armed groups out of the law. The qualitative approach was used in order to go deeply in the players' subjectivity and to unveil their feelings, and the interview in depth and the focal group were performed as gathering data techniques. The narratives were analyzed and categorized using the content analysis technique and the guidelines of the based theory. The results show that the amputation is an episode that changed their lives and led them to a world of uncertainties, challenges and goals that had to overcome together with their relatives and close friends. In this grief the victims found in sitting volleyball a space to find themselves and their pairs, giving again a sense to their lives. Therefore, they conceive the volleyball team as a family that has taught them that limits go beyond the physical condition. 


\section{Introducción}

\subsection{Población en situación de discapacidad}

Se estima que alrededor del 6.3 \% de la población colombiana está en situación de discapacidad (Lugo y Seijas, 2012). Este panorama permite entrever el desafío que hay a nivel social, educativo y político, puesto que los escenarios y proyectos (en su mayoría) son pensados para personas convencionales. Para la Organización Mundial de la Salud (OMS), la discapacidad es la restricción para desarrollar una actividad en los parámetros normales en que se despliegan las personas convencionales (2001). Las personas en situación de discapacidad enfrentan constantemente desafíos que la misma sociedad instaura con la segregación que se evidencia en la inequidad o desventajas para participar activamente en un escenario social donde prevalece la competencia. En este orden de ideas, el despliegue de esta población dentro de su contexto se agudiza de acuerdo a la discapacidad que posea. Jiménez, González y Martin (2001) clasifican la discapacidad en: intelectual, sensorial, psíquica y física. Las personas que se clasifican en la discapacidad física son aquellas que tienen desventajas de movimiento por causas congénitas o adquiridas, limitando el movimiento motor y, por tanto, complejizando los quehaceres cotidianos y laborales. Entre estas discapacidades o deficiencias físicas está la amputación. En Colombia, el número de personas amputadas es considerable y la principal causante de ello son las minas antipersonas, sembradas en la zona rural, que han cobrado la vida y mutilado tanto a personas civiles como militares, siendo estos últimos las principales víctimas (Gutiérrez, 2014; Unicef, 2000).

\subsection{Víctimas de minas antipersonas en Colombia}

Las minas antipersonas son artefactos que se siembran normalmente, en la zona rural, con el objetivo de generar daño físico y psicológico; se activan con el contacto de una persona o animal (UNICEF, 2000). En Colombia, este tipo de artefactos ha cambiado la vida de cientos de personas civiles y militares, que se ven desamparados por el estado y, junto a ello, deben adaptarse a un nuevo estilo de vida colmado de adversidades y desafíos que trastorna sus proyectos de vida. En un estudio mixto que realizó el Instituto Colombiano de Bienestar Familiar (ICBF), la Organización Internacional para las Migraciones (OIM) y el Fondo de las Naciones Unidas para la Infancia (Unicef) se expone que de los 32 departamentos que conforman el territorio colombiano 31 están minados, dejando cientos de víctimas (2014). La siguiente tabla permite ver la dimensión de los daños que han generado las minas antipersonas (MAP), las municiones sin explotar (MUSE) y los artefactos explosivos improvisados (AEI), a la población de este país que lleva más de cinco décadas en un conflicto armado interno que ha coartado su tejido social. 
Víctimas por MAPY MUSE entre 1990 y 2016

\begin{tabular}{|c|c|c|c|c|c|c|}
\hline \multirow[b]{2}{*}{ Aศ๊̆ } & \multicolumn{2}{|c|}{ Civil } & \multicolumn{2}{|c|}{ Fuerza publica } & \multirow{3}{*}{\multicolumn{2}{|c|}{ 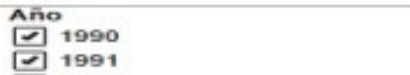 }} \\
\hline & Heride & Muerto & Heride & Muerto & & \\
\hline 1990 & $\mathbf{3}$ & 1 & $\mathbf{n}$ & 11 & & \\
\hline 1991 & 7 & 6 & 46 & 10 & 合 & 1993 \\
\hline 1992 & 30 & 14 & 77 & 30 & $\sigma$ & 1994 \\
\hline 1993 & 27 & 12 & 33 & 12 & Dep & artamento \\
\hline 1994 & 14 & 10 & 48 & 12 & 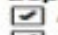 & AMAZONAS \\
\hline 1995 & 27 & 6 & 82 & 15 & G & ANTIOQUIA \\
\hline 1996 & 33 & 11 & 61 & 15 & - & $\begin{array}{l}\text { ARAUCA } \\
\text { ATLANTICO }\end{array}$ \\
\hline 1997 & 36 & 30 & 27 & 3 & N & $\begin{array}{l}\text { ATLANTICO } \\
\text { BOGOTA DC }\end{array}$ \\
\hline 1998 & 28 & 12 & 14 & 4 & Mun & aicipio \\
\hline 1999 & 18 & 10 & 13 & 13 & 曰 & ABEJORRAL \\
\hline 2000 & 60 & 14 & 43 & 21 & 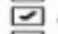 & ÁBREGO \\
\hline 2001 & 137 & 23 & 112 & 29 & 酌 & ABRIAQUI \\
\hline 2002 & 256 & 58 & 234 & 84 & 口 & ACACIAS \\
\hline 2003 & 228 & 62 & 351 & 115 & 凹 & ACANDI \\
\hline 2004 & 226 & 66 & 469 & 136 & Tipe & $\begin{array}{l}\text { de evento } \\
\text { Accidente por MAP }\end{array}$ \\
\hline 2005 & 332 & 92 & 560 & 199 & 两 & $\begin{array}{l}\text { Accidente por MAP } \\
\text { Accidente por MUSE }\end{array}$ \\
\hline 2006 & 368 & 74 & 622 & 168 & & \\
\hline 2007 & 226 & 59 & 537 & 157 & & \\
\hline 2008 & 281 & 69 & 410 & 103 & Ran & $\begin{array}{l}\text { Oo de edad } \\
\text { Mayor de } 18 \text { años }\end{array}$ \\
\hline 2009 & 246 & 57 & 398 & 70 & 更 & Menor de 18 años \\
\hline 2010 & 258 & 7 & 361 & 51 & & \\
\hline 2011 & 174 & 33 & 281 & 65 & & \\
\hline 2012 & 179 & 43 & 253 & 35 & Gen & Dero \\
\hline 2013 & 145 & 20 & 189 & 20 & F & Femenino \\
\hline 2014 & 90 & 9 & 156 & 31 & $\sigma$ & Masculino \\
\hline 2015 & 49 & 17 & 142 & 14 & 凹 & Sospecha de campo minado \\
\hline
\end{tabular}

Fuente: Dirección contra minas (2016)

Las MAP no hacen distinción de raza, género o edad; no obstante, las víctimas en su mayoría son las personas que viven en las zonas rurales y los militares que salen a patrullar por el territorio colombiano. Estas cifras son un llamado a los grupos armados al margen de la ley para que tomen decisiones de fondo y desistan de los campos minados, puesto que están actuando no solo contra los militares sino también contra la población civil.

Si bien todas las MAP no acaban con la vida de las personas que las activan, en su mayoría terminan siendo amputadas, dejando secuelas físicas y psicológicas que impiden la movilidad regular y, en el peor de los casos, de forma autónoma (ICBF el at, 2014). En relación a lo anterior, Ocampo, Henao y Vásquez (2010) plantean que las personas que han sufrido amputación deben hacer diferentes modificaciones, para conservar su funcionalidad, puesto que la separación de una extremidad genera modificaciones a nivel funcional, psicológico y fisiológico, afectando la víctima en todas sus dimensiones.

En Colombia, según la Ley 1448 de 2011, las víctimas son aquellas personas que individual o colectivamente hayan sufrido un daño por hechos ocurridos a partir del $1^{\circ}$ de enero de 1985 , como consecuencia de infracciones al Derecho Internacional Humanitario. Esta postura es bastante reducida si se tiene en cuenta que su objetivo no va más allá de la reparación monetaria, yuxtaponiendo una reparación integral. Por otra parte, el Sistema de Gestión de Información sobre Actividades relativas a Minas Antipersonal considera víctima a aquella persona que haya sufrido una lesión física o psicológica derivada del impacto directo de la explosión de MAP, MUSE o AEI (Dirección Contra Minas, 2016). Según el Registro Único de Víctimas (RUV, 2016), a nivel nacional hay 8.040.748 víctimas registradas, de las cuales 10.924 son por MAP, MUSE y AEI, el número de víctimas es considerable y las políticas gubernamentales son paños de agua tibia para un fenómeno social que requiere de procesos sistémicos y sistemáticos pero, ante todo, de la concientización de los grupos al margen de la ley que han sido protagonistas de un conflicto que involucra y perjudica a toda una sociedad.

\subsection{El deporte adaptado: escenario para la inclusión}

Desde un enfoque recreativo, el deporte propicia diversión, libertad y sano esparcimiento (Ruiz y Cabrera, 2004) pero, ante todo la posibilidad de auto-identificar las destrezas y limitaciones (Giménez, Abad y Robles, 2009). Estas cualidades se afianzan en los deportes adaptados, que han sido pensados y modificados para que lo practiquen personas con capacidades diversas, sin alterar el objeto de la disciplina (Reina, 2014). Son varios los 
deportes (individuales y de conjunto) que han sido adaptados, por ejemplo, en natación, ajedrez, billar, baloncesto en silla de ruedas, fútbol sonoro, voleibol sentado, entre otros.

Si bien el deporte promueve la competencia y, consecuentemente, la negación del otro en el afán de lograr los objetivos, también es un escenario donde los deportistas se encuentran consigo mismos y sus semejantes, fomentando valores como el respecto, la tolerancia, el compañerismo, entre otros valores que tejen relaciones interpersonales que van más allá del encuentro deportivo (Gutiérrez, 2004). En este orden de ideas, el deporte adaptado promueve la inclusión social y, a su vez, es un andamiaje para fortalecer la autoestima de aquellas personas que en su situación de discapacidad han sido invisibilizadas socialmente.

Entre los deportes adaptados de conjunto está el voleibol sentado que aparece en la década de los 70 y 80 . Su objetivo y reglas son similares a las del voleibol convencional; hay algunas variables y ellas son la movilidad de los jugadores quienes deben mantenerse sentados con la pelvis al piso durante todo el juego (Timón y Hormigo, 2010). En la actualidad, en Colombia hay, 14 equipos ubicados en diferentes departamentos, brindando la oportunidad a población en situación de discapacidad a hacer deporte, recrearse y compartir con sus semejantes. Estos equipos participan de torneos zonales para hacer representaciones nacionales, ello incide en que los deportistas asistan a los entrenos y participen activamente de los eventos que se promueven. Los deportes adaptados han ido ganando espacio en los escenarios deportivos y los adeptos cada vez son más, una de las razones es el número considerable de personas que están en situación de discapacidad y las oportunidades que brinda practicar un deporte.

\subsection{El sentido: dinamizador de vida}

La condición humana se da en la interacción con los semejantes (Maturana, 2002), tejiendo lazos que dan sentido a la existencia en un mundo caótico (Berger y Lukmann, 1995). En otras palabras, el sujeto existe o vive porque hay un sostén que da sentido a la vida (Holzapfel, 2005). Siempre se vivirán momentos de adversidad, pero mientras exista una razón para seguir viviendo habrá una luz en la oscuridad (Frank, 1991); a ello se le llama sentido. El sentido se configura mediante cinco generadores: vínculo, cobijo, atadura, reiteración y sostén (Holzapfel, 2005). El vínculo hace referencia a la afinidad que hay con algo o alguien, ello promueve el cobijo que se da mediante la aceptación del otro suscitando protección; vínculo y cobijo dan pie a la atadura que se manifiesta en la unión o amparo por el otro. Estos tres generadores de sentido configuran la reiteración que se materializa en el encuentro constante o tácito con los semejantes, la coexistencia entre vínculo, cobijo, atadura y reiteración generan el sostén, la máxima expresión del sentido que da el soporte a la existencia. Valga aclarar que es un bucle que se retroalimenta en el encuentro y desencuentro con el otro o lo otro, dando sentido a la vida.

Ahondar en el sentido que las personas le dan a algo o alguien es tratar de interpretar la afinidad, cercanía y el grado de satisfacción que su suscita de la relación que los ata (Nancy, 2003). Por ello, la importancia de investigar sobre tópicos como el sentido, puesto que permite develar las emociones, sentires y percepciones que los sujetos dan a los eventos, lugares, semejantes, entre otros, que hacen parte y dan sentido a su vida (Berger y Lukmann, 1995).

\section{Metodología}

Para comprender el sentido que los deportistas en situación de discapacidad física (Amputación) del Club Deportivo Halcones Héroes del Cauca le dan al Voleibol Sentado, el estudio optó por el enfoque cualitativo, puesto que las emociones y sentires difícilmente se cuantifican y, más bien, para ahondar en ellos es necesario escuchar a las personas que configuran su propia historia. Para acopiar los datos se utilizó la entrevista en profundidad y el grupo focal. En cada una de las técnicas participaron cuatro informantes claves que se eligieron por los siguientes criterios de selección: primero, que tuviera amputada una de sus extremidades; segundo, que llevara más de dos años en el club; tercero, liderazgo dentro del grupo; y, cuarto, que haya conformado su propio hogar. Las técnicas de recolección de datos permitieron acopiar información donde los deportistas, desde sus 
propios relatos, evidencian cómo las minas antipersonas y el voleibol sentado han incidido en sus vidas; en otras palabras, mediante la narrativa configuran su propia historia y dan significado a los eventos o sucesos que hacen parte de su trayectoria de vida. Los datos se analizaron bajo la técnica de análisis de contenido, siguiendo los lineamientos de la teoría fundada. Los relatos fueron categorizados en categorías abiertas, axiales y selectivas. En los resultados se expone la categoría selectiva: El deporte es la droga para la gente inteligente, y las axiales que la sustentan: El voleibol sentado un escenario para la inclusión y, posteriormente, Amputación: una segunda oportunidad de vida.

El estudio se realizó con los deportistas de voleibol sentado que hacen parte del equipo Halcones Héroes del Cauca, residente en la ciudad de Popayán (Colombia), Entre los deportistas hay suboficiales y soldados profesionales víctimas de las minas antipersonas, que fueron amputados de miembro superior o inferior. El equipo está conformado por veinte deportistas que se reúnen tres veces a la semana para compartir, entrenar y superar sus propios miedos. Cabe resaltar que ellos representan al Departamento del Cauca en los diferentes torneos regionales y nacionales.

\section{Resultados}

\subsection{El deporte es la “droga” para la gente inteligente}

En el imaginario social, el concepto de droga conlleva a pensar en aspectos negativos, debido a las consecuencias que genera en las personas que se han dejado seducir por ella. No obstante, para los deportistas del Club Deportivo Halcones Héroes del Cauca este concepto es totalmente diferente, el deporte es "la droga" que los ata como grupo y motiva a seguir adelante ante las adversidades físicas y sociales que afrontan constantemente. El deporte los lleva a un estado de confort y anestesia los dolores físicos y psicológicos que les ha dejado las minas antipersona.

El deporte al cual se hace referencia es el voleibol sentado que se ha convertido para ellos en el espacio que les permite encontrase consigo mismos y sus pares, donde no se discrimina o estigmatiza por las huellas imborrables que ha dejado las minas antipersonas en sus cuerpos. Por ello, el voleibol sentado se ha transformado para estos deportistas en un escenario de encuentros y desencuentros donde se olvidan por un instante de los problemas y dolores emocionales que coartan sus sueños. Al respecto uno de los protagonistas de este estudio menciona:

Voleibol sentado me ha regalado muchas cosas, sobre todo la felicidad. Cuando uno está ahí con el grupo (mejor dicho me ha cambiado todo) se entretiene, no piensa en nada sino en su deporte y en cosas positivas, en cosas buenas, eso es lo que me ha regalado voleibol sentado y chévere. (Sj2; En) ${ }^{1}$

Este mismo sentir lo ratifica otro deportista integrante de Halcones, cuando hace referencia a que encontró una nueva familia con características especiales y únicas.

Voleibol sentado se convirtió en una familia que uno... por ejemplo en la casa uno puede estar estresado

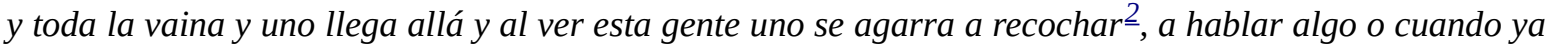
está jugando y alguno la embarra uno no se pone a regañarlo, sino que más bien lo coge en recocha como para que la persona no se sienta mal. (Sj1; En)

Los relatos evidencian que el voleibol sentado, más que un deporte donde hay exigencia física, es un espacio que permite hacer catarsis y liberarse del peso emocional que conlleva el haber perdido un brazo o una pierna. En otras palabras, el voleibol sentado es una familia donde se acepta al otro como otro, propiciando espacio y tiempo para dinamizar procesos de resiliencia. Desde un enfoque recreativo, el deporte contribuye en el fomento de valores y mejora las relaciones interpersonales (Gutiérrez, 2004)

Para ahondar en el sentir y las emociones de los deportistas de voleibol sentado, que tiempo atrás expusieron sus vidas para velar por la soberanía y tranquilidad de un país, se hace necesario interpretar cómo la pérdida de una o varias de sus extremidades, a manos de las minas antipersonas, han marcado sus vidas. En el estudio del ICBF et 
al. (2014) se concluye que las minas antipersonas son unas de las principales agravantes del conflicto armado y las secuelas físicas y psicologías que deja en las víctimas son difíciles de contrarrestar.

\subsubsection{Amputación: una segunda oportunidad de vida}

En su quehacer profesional, los militares se ven expuestos a múltiples riesgos, inclusive hasta la muerte. En los últimos años, uno de los principales enemigos invisibles son las minas antipersonas que han sido sembradas en lugares estratégicos por personas que tienen un objetivo claro: causar daño físico y psicológico a los adversarios. Según el RUV (2016) se han registrado 10.924 víctimas directas de las minas antipersonas, estas cifras son escalofriantes y evidencian el peligro eminente al cual están expuestos los militares y los civiles que transitan por los lugares donde se ha sembrado la muerte.

Las minas han dejado huellas físicas y psicológicas marcando el cuerpo y el espíritu de las víctimas; el dolor que sienten estas personas es un dolor compartido con sus seres queridos que en su manifestación de amor viven su propio duelo. Valga aclarar que los actos victimizantes inciden en lo individual, familiar y, por qué no, lo social (Torres, 2013).

Ante una situación que cambia el rumbo de los proyectos personales y familiares, pueden emerger diferentes respuestas para afrontar los nuevos desafíos, respetable cada una de ellas por la situación que se vive en el momento, puesto que no es fácil asimilar la pérdida de una de las extremidades con la cual se nació y creció. Diferentes investigaciones (ICBF et al, 2014; Torres, 2013; Jaramillo, 2010) mencionan que las víctimas del conflicto viven un trauma psicosocial que afecta su identidad e incide negativamente en las relaciones inter e intrapersonales; no obstante, el impacto o manifestación es diferente en cada una de las víctimas, puesto que las experiencias y vivencias son únicas.

En el caso de los militares que hacen parte del Club Deportivo Halcones Héroes del Cauca, han vivido este duelo con tenacidad y ganas de seguir adelante con los nuevos proyectos, sin desconocer que los primeros episodios fueron de angustia, dolor y desesperanza.

Cuando quedé sin el pie... a mí me daba pena salir a la calle, y que me vieran sin el pie, yo prefería quedarme en la casa viendo televisión o haciendo cualquier cosa o durmiendo, a salir a la calle así... por ahí, cuando uno se mentaliza en lo que está haciendo, como que le echa mente, uno dice bueno yo estoy herido es cierto pero esto es algo que queda en el pasado ya uno no es limitado físico... ya uno es una persona normal (Sj 1; En)

Cuando empecé con limitación física pensaba que ya no sirvo para nada, mejor dicho, ¿qué hago yo sin una pierna? ¿ yo no puedo hacer nada? pero me di cuenta que se pueden hacer muchas cosas. Mejor dicho hacer más que cuando uno está bueno porque ahora hago cosas que no hacía antes (Sj 2; En).

Los relatos evidencian el dolor y la impotencia de no poder hacer nada ante una situación que cambió sus vidas de forma drástica, este episodio quedará tan grabado en sus memorias y en sus cuerpos que no volverán a ser los mismos. Ante esta tempestad que nubla el camino e impide ver más allá del dolor y la incertidumbre hay una luz de esperanza en la familia filial y la familia adoptiva Halcones que han brindado espacio y tiempos colmados de amor, hermandad y fraternidad para buscar nuevos rumbos que le den sentido a la vida, catalogando el estar vivos en una segunda oportunidad que les permite compartir con los seres queridos y proponerse retos que los hacen sentir vivos.

Veo una segunda oportunidad de vida, el simple hecho de estar vivo es una segunda oportunidad que le ha dado Dios a uno, y hay que aprovecharla para hacer cosas buenas como practicar deporte (Sj 2; Gf)

El incidente parte en dos el camino o la línea que uno llevaba antes, como militar mantenía bastante alejado de la familia, ya pasó, después del incidente en el campo minado tuve la oportunidad de acercarme a mi familia y estar al lado de ellos. Ver crecer a mis hijos y fuera de esto conformar otro 
grupo de esparcimiento como el que tenemos en Halcones Héroes del Cauca que es un grupo de familia totalmente diferente (Sj 3; En).

En los procesos de resiliencia es necesario el acompañamiento de un grupo de profesionales que ayuden a hacer catarsis y a canalizar los episodios que hacen daño; sin embargo, la familia es un eje fundamental en este proceso. El ICBF et al (2014) plantean que la resiliencia es más evidente en las víctimas que tienen el acompañamiento de familiares o personas allegadas en la atención psicosocial. En estos deportistas, la familia y el voleibol sentado han sido el tubo de escape para liberarse de las tensiones y buscar nuevos horizontes.

Si bien las minas antipersonas han tocado las fibras más sensibles de estos héroes de la patria, es evidente que han tenido la capacidad de sortear cada uno de los obstáculos con paciencia y sabiduría. Estos procesos de resiliencia les ha permitido aceptar su nueva condición física y sanar las heridas psicológicas que les dejó las MAP.

A pesar del accidente somos afortunados, afortunados pero....no por perder el pie, afortunados por no perder la vida, porque en la amputación yo creo que del 60\% al 70\% pierden la vida”. (Sj 4; Gf)

Yo asimilé mi accidente normal, pues ya qué se va hacer eso fue el destino de mi Dios que me propuso, mejor dicho mi Dios me regaló una nueva oportunidad de vida para seguir adelante y para estar feliz y contento, mi limitación no me da para nada, yo hago mis cosas como si estuviera bueno, no le presto atención y hago como si fuera todo normal, para mi bien todo". (Sj 2; En)

Buscar una luz en la oscuridad no es fácil, pero si hay apoyo y motivación de las personas cercanas (familia y amigos) la marcha en el camino será más llevadera y se buscarán nuevos horizontes que harán de la vida un oasis dentro del desierto. Para estos deportistas, el oasis ha sido su familia y el Club Héroes del Cauca que les ha dado una brisa para sanar las heridas que les ha dejado la guerra.

En el grupo me siento en confianza, porque antes de entrar al equipo siempre me ha gustado que la gente no me vea la discapacidad, yo siempre uso pantalón largo y sudaderas. En mi barrio son muy poquitos los que sabían que yo era discapacitado por ahí dos o tres vecinos, porque yo digamos que desde adentro de la casa me quitaba la prótesis y andaba en bastones e irónicamente se daban cuenta, de puertas para afuera no se daba cuenta nadie (Sj 1; En).

Recuerdo una experiencia en un colegio... todas esas peladitas nos miraban no como discapacitados sino como un grupo, un grupo grande, ellas sé que quedaron admiradas con todo lo que hacíamos... eso es lo que uno representa, de pronto esa seguridad en...” (Sj 3; Gf).

Es evidente que las minas antipersonas han dejado huellas imborrables, cambiando el rumbo de los proyectos personales y familiares; junto a ello, no hay que desconocer que las secuelas físicas no se podrán remediar en su totalidad y las psicológicas requieren de tiempo y acompañamiento profesional para buscar un nuevo sentido a la vida. Si bien las minas antipersonas han generado caos y desorden en la vida de los ex-militares, ha sido el voleibol sentado un bálsamo de tranquilidad para reencontrarse e hilar nuevas redes que dan sentido al camino que se configura en el caminar. En otras palabras, el voleibol es el bastón de apoyo que ha permitido buscar la luz en la oscuridad, que se torna fría, desafiante e inquietante ante la impotencia de no poder remediar lo irremediable, como lo es la pérdida de una de las extremidades físicas. A este ejercicio de sanar las heridas y buscar nuevos caminos se le llama resiliencia. Bascón la concibe como "la capacidad de los sujetos para sobreponerse a periodos de dolor emocional. Se dice que un sujeto o grupo de personas manifiestan una resiliencia adecuada cuando pueden sobreponerse a contratiempos o incluso resultar fortalecidos por los mismos" (citado por Torres, 2013, p. 38). La resiliencia da confianza y seguridad pero, ante todo, da sentido a la vida.

He adquirido bastante seguridad, para poder de pronto que las demás personas lo vean y uno no le importa lo que digan o que lo queden mirando. Al contrario, es mejor que miren qué es lo bueno que uno hace y lo que se puede hacer... (Sj 4; Gf) 
Ahora nos pueden llamar a cualquier lado y le llegamos hasta en pantalonetas, ya no nos da pena de nada... ipara que ellos nos miren! Y por eso creo que es muy positivo voleibol sentado, nos ha abierto de pronto la mente y gracias a esto ya somos bastantes tolerantes con las demás personas...” (Sj 3; Gf).

Este deporte les ha brindado la oportunidad de crear nuevas rutas para buscar desafíos que los hace sentir vivos e importantes dentro de una sociedad excluyente, mejorando su autoestima e identidad. Por consiguiente, el club Halcones dinamiza una identidad colectiva que fortalece el grupo y ata a sus adeptos. Mercado y Hernández (2010) manifiestan que es la identidad colectiva la que permite que una cultura o grupo se recree y exista en el tiempo.

El club Halcones Héroes del Cauca se ha mantenido como grupo porque los deportistas encuentran en él un escenario donde no hay discriminación y se sienten en familia pero, ante todo, les ha enseñado que las limitaciones van más allá de la condición física

\subsubsection{La condición física no es el límite: el límite es mental}

Como se ha expuesto, el voleibol ha sido un espacio donde los deportistas se han encontrado con ellos mismos, en la aceptación del otro como otro. Es en este proceso de alteridad donde se afincan valores como el respeto, la honestidad y el compañerismo, fundamentales para crear lazos filiales entre personas que sufren el mismo dolor. Uno de los sujetos investigados expone:

El grupo halcones del cauca ayudó pues a fortalecer de pronto todos esos miedos que tenía ante la sociedad porque encontré en el grupo personas en igual condiciones que las mías y nos dimos apoyo mutuo, contando las experiencias y las situaciones que le pasó después del incidente, en cómo nos miraban la gente y la sociedad. Este grupo pues ayudó a fortalecer para poder sin miedo darnos a conocer ante la sociedad, porque en el grupo eso es lo que estamos haciendo (Sj 3;En).

El equipo me ha dado más seguridad y confianza, ahora salgo a la calle en bastones y si me toca salir con la pata ahí normal, también salgo en pantaloneta y normal. Ese miedo o ese qué dirá de la gente se quedó atrás (Sj 1; En).

Es evidente que el dolor y las incertidumbres son llevaderas cuando se comparte con personas que tienen características similares y que buscan un mismo objetivo, en este caso, visibilizarse ante la sociedad como personas regulares que sienten, piensan, se emocionan y tienen sueños, es decir, no ser estigmatizados por su condición física o en el peor de los casos ser víctimas de esa mirada que evidencia lástima, haciéndoles sentirse inferiores ante sus semejantes. Una de las principales características de las víctimas de las minas antipersonas es la falta de confianza en sí mismos y, consecuentemente, la dificultad para interactuar con sus semejantes (ICBF et al, 2014).

El duelo que viven las víctimas es más llevadero cuando hay un grupo con el que se identifican y tienen similitudes, en otras palabras, cuando hay una identidad colectiva. Mercado y Hernández (2010) plantean que la identidad colectiva se configura cuando los sujetos que hacen parte del grupo tienen afinidades y se sienten cómodos en el compartir, dándole sentido a cada una de las vivencias que se promueven en y por el grupo. En el caso de los deportistas de Halcones, es el trabajo en equipo y las ganas de seguir adelante que les ha permito ser conscientes de que la vida está llena de obstáculos y que para superarlos es necesario tener voluntad y creer en sí mismo. De ahí la convicción de que los límites no son físicos sino mentales. Uno de los deportistas expone una de sus vivencias en una fiesta, para dar cuenta que cuando se quiere algo se logra.

Yo le dije vamos a bailar y ella decía no... que no... que usted no puede y dije; ah... bueno listo... vale... no pasa nada! empecé yo ahora sí por mi cuenta a bailar con otras viejas...jAy! ustedes me hubieran visto ese día... todos los que estaban... los que habían ido conmigo ese día me decían ¿pero vos cómo haces? Y le respondí todo está aquí (señala con el dedo la sien), es cierto no se puede mover lo mismo pero hago el intento, cualquier cosa saco, bailaba salsa, merengue cualquier cosa pero hacía el intento y 
todos decían jve vos bailas qué bacanoํㅡ ( $\mathrm{Sj} 1$; Gf).

Ante la limitación física y las ganas de participar de los eventos sociales y deportivos es evidente que los obstáculos van más allá de la condición física, siendo la autoestima y la personalidad los detonantes para desafiar los retos. Los procesos de resiliencia contribuyen a que las víctimas logren salir del anonimato, tengan autoconfianza y den sentido a sus vidas (Torres, 2013; Latorre, 2010; ICBF et al, 2014).

Siempre me mentalizaba, si ellos pueden los que están alentados yo por qué no voy a poder, todo existe en la mente... entonces yo me mentalicé... ya todos los días a entrenar de 6 de la mañana a 10 de la mañana todos los días (Sj 4; En).

Las relaciones interpersonales que se tejen en el grupo han permitido a sus adeptos ser conscientes que viven dentro de una sociedad pensada para personas regulares, por tanto, deberán enfrentar constantemente obstáculos que los desafían, pero los hacen sentir vivos. Es en la coyuntura de la incertidumbre donde se reflexiona que hay otras posibilidades de vivir y enfrentar el día a día. Este proceso de resiliencia ha permitido a los deportistas ser conscientes que la limitación física no es un límite para lograr sus objetivos; por el contrario, es un aliciente para transitar rutas que seguramente las personas convencionales no se atreverían a transitar.

Los relatos de estas personas que han sido víctimas de las minas antipersonas dan cuenta que los duelos y retos que han enfrentado no han sido fáciles de superar, pero las ganas de seguir viviendo les ha dado las fuerzas y la esperanza para continuar con sus proyectos, siendo la familia y el voleibol sentado los ejes que dan el soporte para sobrellevar las cargas emocionales y físicas que enfrentan constantemente. Estas historias de vida evidencian la complejidad que conlleva el ser víctima del flagelo de las minas antipersonas pero, ante todo, que en la adversidad hay alternativas que permiten darle sentido a la vida; junto a lo anterior, que los obstáculos son parte del camino que construimos con el andar y, por otra parte, que el deporte brinda escenarios donde confluyen emociones que hacen sentir vivos a quienes lo practican.

\section{Conclusiones}

El presente estudio evidencia cómo las minas antipersonas han cambiado la vida de los sujetos qua han sido víctimas de este flagelo y, consecuentemente, las de sus familiares y allegados. Ante un episodio devastador que deja huellas imborrables las víctimas se sumergen en la depresión y baja autoestima, coartando las proyecciones personales y familiares; en otras palabras, el sentido de la vida se desvanece en las angustias e incertidumbres que hacen parte de su nueva realidad (Torres, 2013; Jaramillo, 2010). En efecto, estas personas son revictimizadas por una sociedad que excluye y estigmatiza a quienes, por razones congénitas, genéticas o accidentes, no cuentan con todas sus extremidades. Los deportistas de Halcones Héroes del Cauca han tenido que vivir este tipo de episodios que son más dolorosos que la misma amputación, pero a la vez los desafía a buscar nuevos caminos que los hace sentir vivos, en una atmósfera que se respira exclusión.

Ante esta problemática, los deportistas han encontrado en el voleibol sentado una familia donde comparten, se recrean pero, ante todo se acepta al otro como otro. Valga aclarar que es un escenario donde liberan tensiones y se olvidan por un instante de sus problemáticas; junto a lo anterior, les ha permitido descubrir otras habilidades, compartir más tiempo con sus familias y hacer actividades que en la vida militar no realizaban. Este proceso de resiliencia ha incidido en que los deportistas conciban este episodio traumático en una segunda oportunidad de vida. Esta es la importancia de promover espacios y tiempos para generar procesos de resiliencia en las víctimas de un conflicto que ha coartado el tejido social y familiar (Torres, 2013; Latorre, 2010)

Las adversidades que han sorteado en los diferentes escenarios sociales les ha enseñado que las limitaciones van más allá de la condición física. La actitud y las ganas de seguir adelante son aspectos que hacen la diferencia en las proyecciones y materialización de los objetivos que se trazan. En este sentido, los deportistas de Halcones son un ejemplo para las personas que están en su misma condición física y que por diferentes motivos se han invisibilizado socialmente pero, ante todo, son un ejemplo para las personas convencionales que teniendo todas 
las condiciones físicas se rinden ante el primer obstáculo.

Junto a lo anterior, es necesario pensar en una sociedad incluyente que piense y actúe en pro de las personas en situación de discapacidad. En nuestro país se habla de un posconflicto, y en las instituciones educativas se promueve la cátedra de la paz, pero la paz no es ausencia de balas, ella se logra cuando se contrarresta la violencia estructural y simbólica; en otras palabras, cuando hay igualdad de condiciones y los derechos no se vulneran (Muñoz, 2013). En la Ley 181 de 1995 se manifiesta el derecho al deporte, la recreación y al uso del tiempo libre independientemente de la condición física; este derecho de una u otra manera es vulnerado, puesto que los escenarios e implementos deportivos no se garantizan a toda la población, en especial a las personas en situación de discapacidad que requieren escenarios que se ajusten a sus capacidades. En este sentido, los entes gubernamentales que velan para que esta ley se cumpla tienen un compromiso con la sociedad y en particular con las víctimas del conflicto armado que deben adaptarse, desde su nueva realidad, a una sociedad cada vez más excluyente.

En esta coyuntura social de desigualdad y exclusión en que están inmersas las personas en situación de discapacidad, emergen los deportes adaptados como una oportunidad para recrearse, compartir con sus pares y, sobre todo, sentirse vivos. Por ello, el voleibol sentado para los deportistas de Halcones Héroes del Cauca es más que un deporte, es una familia que ha dado sentido a sus vidas.

Lo expuesto anteriormente permite evidenciar que el conflicto armado interno en Colombia ha coartado el tejido social, dejado huellas imborrables en el cuerpo y la memoria de las personas que han sido víctimas directas e indirectas de este fenómeno socio-político (ICBF el at, 2014; Torres, 2013; Jaramillo, 2010; Latorre, 2010). Ante un posible posconflicto, el deporte debería tenerse en cuenta como medio pedagógico para resocializar a las personas que han hecho parte de los grupos al margen de la ley; por otra parte, puede ser tenido en cuenta en la rehabilitación física de aquellas personas que han sufrido secuelas en sus cuerpos. Valga aclarar que el deporte, desde un enfoque recreativo, es constructor de tejido social y dinamizador de relaciones "imposibles", puesto que permite la interacción con los semejantes (independiente de raza, genero, ideologías políticas o grupos armados) y fomenta valores como el respeto, tolerancia, honestidad, compañerismos, entre otros (Giménez et al, 2009). Valores que se han yuxtapuesto en la lucha de una guerra absurda que ha perdido su horizonte y que es necesario recuperarlos si se pretende construir un país más humano, donde los derechos no se vulneren y haya igualdad de condiciones; en este sentido, se estaría hablando de una verdadera paz que trasciende de los acuerdos que reposan en los documentos.

\section{Notas}

1 Los párrafos que están en cursiva son los relatos que emergieron de las entrevistas y el grupo focal. Se colocan en este tipo de letra para que se diferencien dentro del texto. El código que acompaña a los relato permite evidenciar el sujeto que lo manifiesta y la técnica que se utilizó para acopiar la información, por ejemplo, Sj1= sujeto número uno; En= entrevista; $\mathrm{Gf}=$ grupo focal. Estos códigos se han utilizado para salvaguardar la identidad de las personas participaron de la investigación.

2 Léxico coloquial para referirse al desorden o indisciplina

$\underline{3}$ Léxico coloquial para referirse a agradable o bien

\section{Referencias bibliográficas}

Berger, P y Lukmann, T. (1995). Modernidad pluralismo y crisis de sentido. España: Paidos.

Colombia. Congreso Nacional de la República. Ley 1448 de 2011. Recuperado de http://wsp.presidencia.gov.co/Normativa/Leyes/Documents/ley144810062011.pdf 
Colombia. Congreso Nacional de la República. Ley 181 de 1995. Recuperado de http://www.mineducacion.gov.co/1621/articles-85919 archivo pdf.pdf

Dirección Contra Minas. (2016). Víctimas de minas antipersonas. Recuperado de http://www.accioncontraminas.gov.co/estadisticas/Paginas/victimas-minas-antipersonal.aspx

Fondo de las Naciones Unidad para la Infancia. (2000). Colombia y las minas antipersonal. Sembrando minas cosechando muerte. Colombia: Unicef

Frank, V. (1991). El hombre en búsqueda del sentido. España: Editorial Herder.

Giménez, J; Abad, M y Robles, J. (2009). La enseñanza de deporte desde la perspectiva educativa. Wanceulen E.F Digital, 5 , 91-103. Recuperado de http://rabida.uhu.es/dspace/bitstream/handle/10272/3316/b15548818.pdf? sequence $=1$

Gutiérrez, M. (2004). El valor del deporte en la formación integral del ser humano. Revista de Educación, 335, pp. 105-126. Recuperado de http://www.revistaeducacion.mec.es/re335/re335_10.pdf

Holzapfel, C.(2005). En búsqueda del sentido. Chile: Editorial sudamericana.

Instituto Colombiano de Bienestar Familiar, Organización Internacional para las Migraciones y Fondo de las Naciones Unidas para la Infancia. (2014). Impacto del conflicto armado en el estado psicosocial de niños, niñas y adolescentes. Colombia: ICBF.

Jiménez, M.T., González, P., \& Martín, J.M. (2002) La Clasificación Internacional Del Funcionamiento de la Discapacidad y de la Salud (CIF) 2001. Revista Española de Salud Pública, 76 (4), 271-279.Recuperado de http://scielo.isciii.es/pdf/resp/v76n4/colabora.pdf

Jaramillo, F. (2010). La reconstrucción de la memoria histórica del conflicto colombiano en el actual proceso de justicia y paz. Alcances, desafíos y preguntas. Desafios, 22 (2), 31-69. Recuperado de file:///D:/Archivos\%20del \%20Sistema/Downloads/1411-5236-3-PB.pdf

Lugo, L. H \& Seijas, V. (2012). La discapacidad en Colombia: una mirada global. Revista Colombiana de Medicina Física y Rehabilitación, 22 (2), 164-179. ISSN: 22-56-5655

Latorre, E. L. (2010). Memoria y resiliencia. Estudio de la memoria de las víctimas del conflicto armado en el departamento del magdalena: presentificación, visibilización, catarsis y resiliencia. Prolegómenos-Derechos y valores, 13 (25), 95-109. ISSN: 0121-182X

Muñoz, E. (2013). Educar para la paz: una salida al conflicto armado. Pútchipu, 26, 20-22. Recuperado de http://www.coalico.org/images/stories/boletinputchipu26 web.pdf.

Mercado, A y Hernández, A. V. (2010). El proceso de la construcción de la identidad colectiva. Revista de Ciencias Sociales, 53, pp. 229-251. ISSN: 1405-1435.

Maturana, H. (2002). Transformación de la convivencia. Chile: DOLMEN EDICIONES S.A.

Nancy, J. (2003). El sentido del mundo. Argentina: La marca editora.

Ocampo, M.L., Henao, L.M \& V, L. (2010). Amputación de miembro inferior: cambios funcionales, inmovilización y actividad física. Colombia: Editorial Universidad del Rosario.

Organización Mundial de la Salud. (2001). Informe mundial sobre la discapacidad. Recuperado de http://www.who.int/disabilities/world report/2011/accessible es.pdf

Registro Único de Víctimas. (2016). Número de víctimas registradas. Recuperado de http://rni.unidadvictimas.gov.co/RUV

Reina, R. (2014). Inclusión en deporte adaptado: dos caras de la misma moneda. Psichology, Society \& Education, 
6 (1), 55-67. ISSN: 1989-709X

Ruiz, G y Cabrera, D. (2004). Los valores en el deporte. Revista de Educación, 335, 9-19. Recuperado de http://www.revistaeducacion.mec.es/re335/re335 03.pdf

Tesis (de especialización): Gutiérrez, D.C. (2014). La degradación de las minas antipersonales, una guerra bajo tierra. Universidad militar nueva granada. (Tesis de especialización). Bogotá, Colombia: Posgrado de Relaciones Internacionales y Estudios Políticos, Universidad Militar Nueva Granada.

Torres, F. (2013). Intervención profesional desde la consultoría con enfoque resiliente en familias víctima del conflicto armado. Tendencias \& Retos, 18 (1), 33-48. ISSN: 0122-9729.

Timón, M.L \& Hormigo, F. (2010). El voleibol en la escuela: nuevos enfoques metodológicos y actividades para su Enseñanza en la Escuela. España: Editorial Wanceulen deportiva, SL. 